\title{
755-nm Alexandrite Laser for the Treatment of Non-Facial Superficial and Nodular Basal Cell Carcinoma
}

\author{
Valerie Shiu, MD1, Margaret E Brown, MD1, Pavela Bambekova, MD¹, Jenny Yeh, MD¹, \\ Jacqueline Brogan, $\mathrm{MD}^{1}$, Catherine Kowalewski, DO² \\ ${ }^{1}$ Division of Dermatology \& Cutaneous Surgery, University of Texas Health Science Center at San Antonio, San \\ Antonio, TX \\ ${ }^{2}$ South Texas Veterans Health Care System, San Antonio, TX
}

\section{ABSTRACT}

Background: There is emerging literature regarding laser therapy as a treatment for non-melanoma skin cancer, with reports of vascular selective lasers and ablative lasers showing promise in basal cell carcinoma (BCC).

Objectives: To assess the efficacy of the 755-nm laser in the treatment of non-facial BCC of the superficial and nodular subtypes. To provide patients with a non-surgical option for the treatment of BCC.

Methods: Nineteen veterans, each with at least one biopsy proven superficial or nodular BCC on the trunk or extremity, agreed to participate in our IRB-approved, prospective, non-randomized, open-label clinical trial. A total of $21 \mathrm{BCC}$ were treated, after local anesthetization, using the $755-\mathrm{nm}$ Alexandrite laser (Gentle-Lase, Candela Corporation) in a single session with a $4 \mathrm{~mm}$ margin. Treatment sites were rebiopsied approximately six weeks later.

Results: Twenty-one of 21 treated BCC demonstrated complete histologic tumor resolution at 6-week follow-up. At six weeks, all patients had a scar, and some patients had associated crusting, scaling or ulceration. The high energy and absence of dynamic cooling in our study likely resulted in additional thermal damage to the tumors. Healing times and scar appearance were comparable to electrodesiccation and curettage sites.

Limitations: Our study was limited by a small sample size, lack of a control group, and sampling of treatment sites with shave removal rather than complete excision.

Conclusion: The 755-nm laser has vessel-selective properties and a greater depth of penetration compared to vascular selective lasers. Our study results suggest that the $755-\mathrm{nm}$ Alexandrite laser may be an effective treatment for superficial and nodular BCC on the trunk and extremities. Further investigation is warranted.

\section{INTRODUCTION}

Laser therapy has a wide variety of clinical applications in dermatology. There is emerging literature regarding laser therapy as a treatment for non-melanoma skin cancer, particularly for patients who are not surgical candidates. The greatest promise has been shown in the treatment of basal cell carcinoma (BCC) with vascular and ablative lasers. ${ }^{1}$ In 2011, Ibrahimi et al. 
described success in treating multiple basal cell carcinomas in a single patient with Basal Cell Nevus syndrome using the 755-nm Alexandrite laser. ${ }^{2}$ No subsequent studies, to our knowledge, have further investigated the 755-nm laser in the treatment of BCC.

\section{METHODS}

We designed a prospective, nonrandomized, open-label clinical trial to further assess the efficacy of the 755-nm Alexandrite laser in the treatment of nonfacial BCC of the superficial and nodular subtypes. The study was approved by the Institutional Review Board at the South Texas Veterans Health Care System. Nineteen veterans, each with at least one biopsy-proven superficial or nodular BCC on the trunk or extremity, agreed to participate in our study. Exclusion criteria included tattoos overlying the affected or adjacent skin, photosensitivity, medications in which infrared light is a contraindication, pregnancy, light-induced seizure disorder, active infection of the treatment area, or if the treatment area was overlying an implantable cardiac device. A total of 21 BCC were treated. Following local anesthetization with intralesional $1 \%$ lidocaine without epinephrine, the tumor site and a 4-millimeter margin of clinically normal-appearing surrounding tissue were treated in a single session using the 755-nm Alexandrite laser (Gentle-Lase, Candela Corporation). The following settings, identical to the settings used in the initial report by Ibrahimi et al., were utilized: 8 millimeter spot size, two passes at an energy of $100 \mathrm{~J} / \mathrm{cm} 2$, pulse length of 3 milliseconds, no dynamic cooling mode, and $10 \%$ overlapping of treated tissue between pulses. Treatment resulted in an eschar in all cases. Post-laser wound care involved petrolatum jelly and a non-stick dressing.
The treatment sites were then re-biopsied using a broad shave technique approximately six weeks later.

\section{RESULTS}

Twenty-one of 21 treated BCC demonstrated complete histologic tumor resolution (Table I). Clinically, treatment sites demonstrated similar healing as electrodesiccation and curettage sites, with healing over several weeks and resultant round scar (figure I). The subjects will continue to be followed at least twice annually for five years after the treatment.

\section{DISCUSSION}

Our study was limited by a small sample size, lack of a control group, and sampling of treatment sites with shave removal rather than complete excision. Nonetheless, the results of our study suggest that the 755-nm Alexandrite laser may be an effective treatment for superficial and nodular BCC on the trunk and extremities in patients who do not desire surgery, and we believe that further investigation is warranted.

The Alexandrite laser is known to have vessel-selective properties as well as a greater depth of penetration compared to vascular selective lasers, such as the pulsed-dye laser (PDL). ${ }^{2}$ These properties could explain the mechanism for the complete treatment of BCC in our subjects. Additionally, the high energy in the absence of dynamic cooling likely resulted in significant thermal damage to the BCC sites. It is important to note that scar outcomes following the 755-nm Alexandrite laser treatment of the BCC sites were not better than treating BCC sites with electrodesiccation and curettage (ED\&C), and therefore the patient and the provider 
Table 1.

\begin{tabular}{|c|c|c|c|c|c|c|}
\hline Patient & $\begin{array}{l}\text { Location } \\
\text { of BCC }\end{array}$ & $\begin{array}{l}\text { Histologic } \\
\text { Subtype of } \\
\text { BCC }\end{array}$ & $\begin{array}{c}\text { Size of } \\
\text { BCC }(\mathbf{c m})\end{array}$ & $\begin{array}{c}\text { Clinical } \\
\text { appearance } \\
\text { immediately after } \\
\text { treatment }\end{array}$ & $\begin{array}{l}\text { Pathology, } \\
\text { shave biopsy, } \\
6 \text { weeks after } \\
\text { treatment }\end{array}$ & $\begin{array}{c}\text { Clinical } \\
\text { appearance } \\
6 \text { weeks after } \\
\text { treatment }\end{array}$ \\
\hline 1 & Back & $\begin{array}{c}\text { Superficial \& } \\
\text { Nodular }\end{array}$ & $0.4 \times 0.4$ & eschar & No residual BCC & scar with scale \\
\hline 2 & PUE & Superficial & $0.6 \times 0.6$ & eschar & No residual BCC & scar \\
\hline 3 & Back & Superficial & $1.3 \times 1.2$ & eschar & No residual BCC & scar \\
\hline 4 & Shoulder & Superficial & $1.5 \times 1.5$ & eschar & No residual BCC & scar with crust \\
\hline 5 & Shoulder & Nodular & $0.5 \times 0.5$ & eschar & No residual BCC & scar with scale \\
\hline 6 & Back & Nodular & $0.8 \times 0.8$ & eschar & No residual BCC & scar with crust \\
\hline \multirow{2}{*}{7} & DUE & Superficial & $1.3 \times 0.8$ & eschar & No residual BCC & scar with crust \\
\hline & Shoulder & Superficial & $1.5 \times 1.3$ & eschar & No residual BCC & scar with crust \\
\hline 8 & Clavicle & Superficial & $1.1 \times 0.6$ & eschar & No residual BCC & scar \\
\hline 9 & Back & Nodular & $0.6 \times 0.5$ & eschar & No residual BCC & scar \\
\hline \multirow[b]{2}{*}{10} & Shoulder & Superficial & $1.0 \times 1.0$ & eschar & No residual BCC & scar \\
\hline & PUE & $\begin{array}{l}\text { Superficial \& } \\
\text { Nodular }\end{array}$ & $0.5 \times 0.5$ & eschar & No residual BCC & scar \\
\hline 11 & Shoulder & Superficial & $2.0 \times 1.7$ & eschar & No residual BCC & $\begin{array}{l}\text { scar with } \\
\text { eschar }\end{array}$ \\
\hline 12 & Back & Nodular & $0.6 \times 0.5$ & eschar & No residual BCC & scar \\
\hline 13 & DUE & Superficial & $1.5 \times 1.5$ & eschar & No residual BCC & $\begin{array}{l}\text { scar with } \\
\text { eschar }\end{array}$ \\
\hline 14 & Back & $\begin{array}{l}\text { Superficial \& } \\
\text { Nodular }\end{array}$ & $0.8 \times 0.3$ & eschar & No residual BCC & scar with scale \\
\hline 15 & Shoulder & Nodular & $0.9 \times 0.7$ & eschar & No residual BCC & $\begin{array}{l}\text { scar with } \\
\text { eschar }\end{array}$ \\
\hline 16 & PUE & Superficial & $1.0 \times 1.0$ & eschar & No residual BCC & $\begin{array}{l}\text { scar with } \\
\text { eschar }\end{array}$ \\
\hline 17 & Chest & Nodular & $0.4 \times 0.4$ & eschar & No residual $\mathrm{BCC}$ & $\begin{array}{l}\text { scar with } \\
\text { eschar }\end{array}$ \\
\hline 18 & Back & $\begin{array}{l}\text { Superficial \& } \\
\text { Nodular }\end{array}$ & $0.5 \times 0.5$ & eschar & No residual BCC & scar \\
\hline 19 & Back & $\begin{array}{c}\text { Superficial \& } \\
\text { Nodular }\end{array}$ & $0.7 \times 0.5$ & eschar & No residual $\mathrm{BCC}$ & scar \\
\hline
\end{tabular}

PUE, Proximal Upper Extremity; DUE, Distal Upper Extremity 
Figure 1. Pre, Immediately Post, and 6 Weeks Post Procedural Images of BCC Sites Treated with Laser Therapy.

\section{Before Procedure}
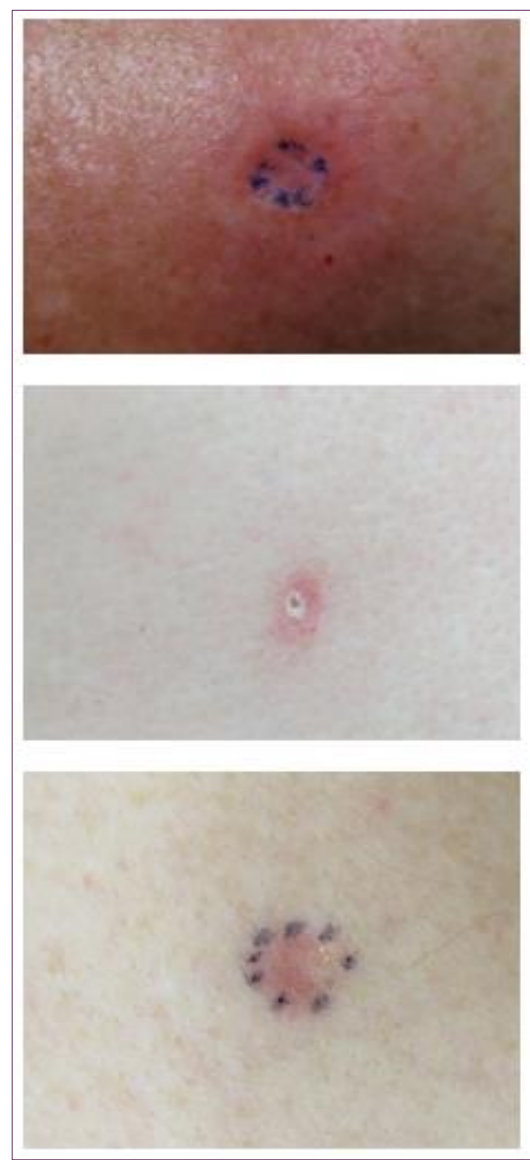

Immediately Post-Procedure
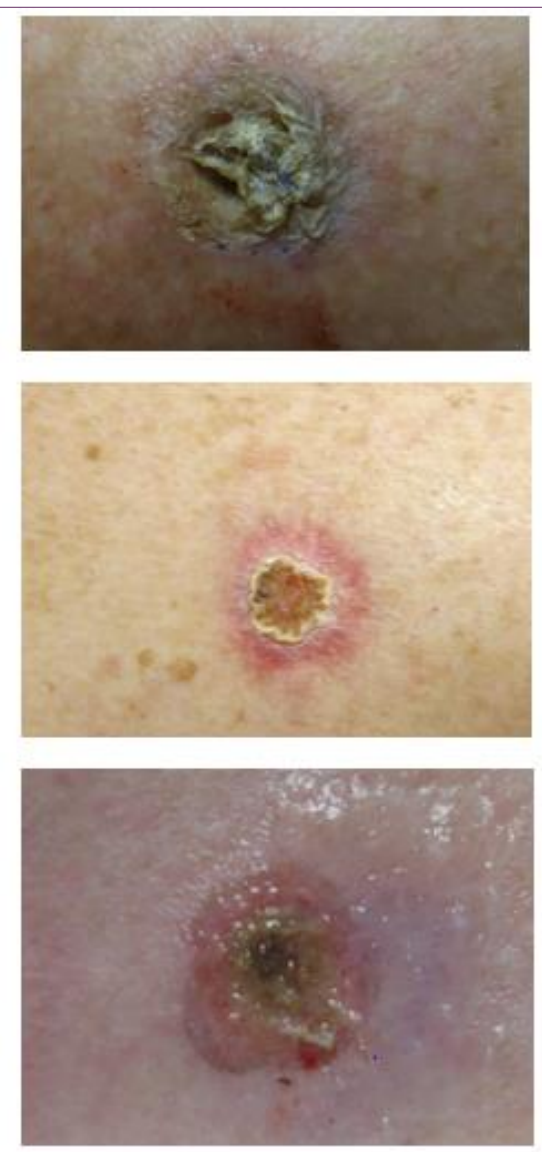

6 Weeks Post-Procedure
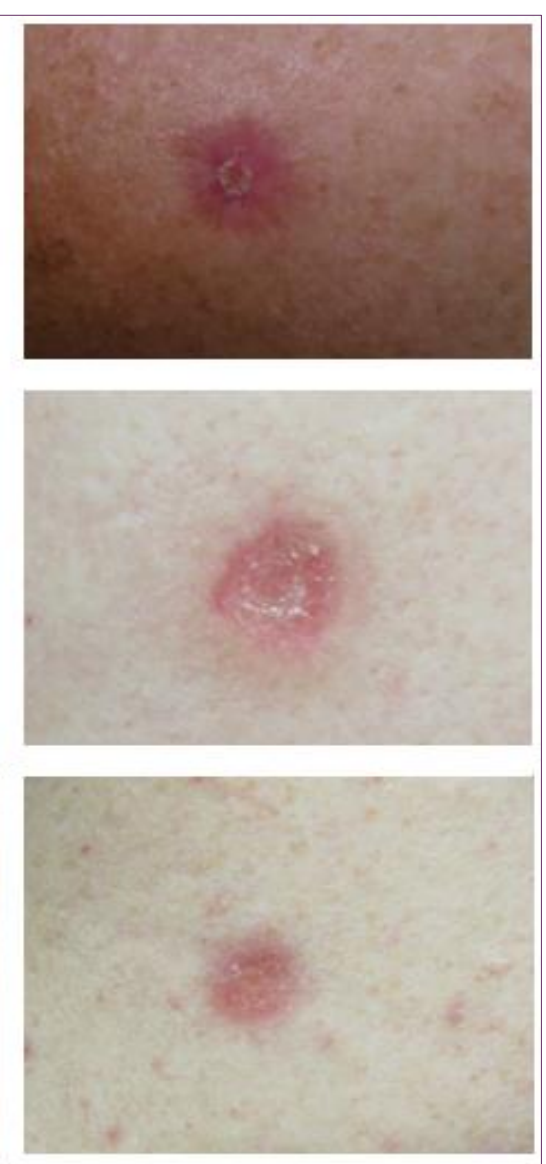

should consider the cost effectiveness between different treatment modalities when making decisions regarding BCC treatments.

\section{Conflict of Interest Disclosures: None}

Funding: None

Corresponding Author:

Pavela Bambekova, MD

Dermatology Clinic, Mays Cancer Center 7979 Wurzbach Rd., Mail Code 7876

San Antonio, TX 78229

bambekova@uthscsa.edu

\section{References:}

1. Soleymani T, Abrouk M, Kelly KM. An Analysis of Laser Therapy for the Treatment of Nonmelanoma Skin Cancer. Dermatol Surg. 2017 May;43(5):615-624. doi: 10.1097/DSS.0000000000001048.

2. Ibrahimi OA, Sakamoto FH, Tannous Z, Anderson RR. $755 \mathrm{~nm}$ alexandrite laser for the reduction of tumor burden in basal cell nevus syndrome. Lasers Surg Med. 2011 Feb;43(2):6871. doi: 10.1002/lsm.2095 